\title{
Identidades dos processos educacionais especializados na Aldeia de Santa Rosa do Oco’y
}

\section{Identities of specialized educational processes in the Village of Santa Rosa Oco’y}

\author{
Andreia Nakamura BONDEZAN* \\ UNIOESTE \\ Eloá Soares Dutra KASTELIC** \\ UNIOESTE \\ Valdene Nogueira ROCHA*** \\ NRE/Foz do Iguaçu
}

Resumo: O presente artigo trata da educação dos indígenas Avá-guarani situados no Oeste do Paraná, especificamente na aldeia de Santa Rosa do Oco’y. Tem como objetivo apresentar como está organizado o ensino para os indígenas com deficiência na referida comunidade. Para isso, aborda as principais características da aldeia de Santa Rosa do Oco’y; os níveis e modalidades de educação ofertada neste local. Por fim, destaca o processo de construção de uma sala de recursos multifuncionais para o atendimento dos alunos que apresentam alguma deficiência. Podemos concluir com este trabalho que a sala de recursos multifuncionais foi uma conquista para que os alunos tivessem a oportunidade de terem suas especificidades atendidas. No entanto, ainda é preciso que se tenham políticas de formação de professores para que este atendimento seja realizado por professor, preferencialmente indígena. Dessa forma, se atenderiam não só as necessidades dos alunos, mas, sobretudo, se faria valer o direito constitucional que garante aos povos indígenas o acesso a processos próprios de aprendizagem. Para realização desse artigo recorremos aos escritos de Cuche (1999) e Hall (2004) e aos documentos: Estatuto do Índio em 1973 (BRASIL, 1973); Constituição Brasileira de 1988 (BRASIL, 1988); Lei de Diretrizes e Bases da Educação Nacional n. 9.394/96 (BRASIL, 1996). As incursões nesses documentos objetivaram buscar entendimento sobre os direitos dos indígenas a uma educação diferenciada, atendimento às especificidades culturais e processos próprios de aprendizagem.

Palavras-chave: Educação escolar indígena. Educação especial na escola diferenciada. Identidades dos processos Educacionais Especiais na escola indígena.

Abstract: This article deals with the education of Ava-Guarani indigenous situated in the West of Paraná, specifically in the village of Santa Rosa Oco’y. It aims to show how the teaching for indigenous with disability is organized in that community. In order do do this, it discusses the main features of the village of Santa Rosa Oco'y; the levels and types of education offered at this location. Finally, it highlights the process of building a multifunctional resources room for the attendance of students who have a disability. The conclusion is that the multifunctional resources room

\footnotetext{
* Doutora em

Educação.

an.bondezan@

hotmail.com

${ }^{* *}$ Doutora em

Letras e Linguística. eloasoares@hotmail. com

*** Especialista em Educação Especial. valdene_rocha@ hotmail.com
} 
was an achievement so that students had the opportunity to have their specificities met. However, it is still necessary to have policies of teacher training so that this assistance is preferably carried out by an indigenous teacher thus not only meet the needs of students, but especially to enforce the constitutional right that guarantees indigenous peoples access to their own learning processes. The references used in this article were Cush (1999), Hall (2004) and documents: Indian Statute in 1973 (BRASIL, 1973), the 1988 Brazilian Constitution (BRASIL, 1988), Law of Guidelines and Bases of National Education n. 9.394/96 (BRASIL, 1996). The incursions within these documents aimed to seek understanding on the rights of indigenous peoples to a differentiated education, attendance to their cultural specificities and their own learning processes.

Keywords: Indigenous school Education. Special Education school in differentiated schools. Identities of Special Educational processes in indigenous schools.

\section{Introdução}

Este artigo insere-se no debate sobre os indígenas Avá-guarani situados no Oeste do Paraná, especificamente na aldeia de Santa Rosa do Oco’y. O presente texto tem como objetivo discutir acerca da educação dos indígenas que apresentam alguma deficiência na referida comunidade.

A identidade dos Avá-guarani vem despontando na historiografia indígena a partir do olhar deste povo sobre seu próprio processo identitário. Nesse sentido compreende-se que identidade é algo sempre incompleto, num processo de construção e desconstrução cotidiano que se insere na dinâmica social. Nessa perspectiva não cabe uma análise essencialista, pois a compreensão é de uma identidade fragmentada que está em constante processo, apresentando suas diversas faces (HALL, 2004).

O trabalho com os povos indígenas tem sido acompanhado de uma inserção na noção de cultura por entender que o elemento cultural perpassa toda a formação desse seguimento social. Compreender a cultura representa conhecer mais sobre as especificidades de cada grupo e subgrupo, o que proporciona às pesquisas maior aproximação com a realidade. Nessa direção, Cuche (1999) contribui quando afirma que “[...] o outro não é nunca absolutamente outro e que há sempre algo de nós nos outros, porque a humanidade é uma só e a Cultura está no centro das culturas [...]” (CUCHE, 1999, p. 243).

Ao priorizar as pesquisas com minorias aqui representadas pelos indígenas, pretende-se atender a um direito constitucional, o qual resguarda aos povos indígenas o direito aos processos próprios de aprendizagem.

Os dados que são apresentados neste trabalho foram gerados na aldeia nos anos de 2010 a 2013. Seus pesquisadores analisaram estes dados a partir das informações geradas em campo e recebidas do Núcleo Regional 
de Educação de Foz do Iguaçu, compondo, dessa forma, um escrito que demonstra, dentro do limite das possibilidades de pesquisa, bem como das páginas de um artigo, como pôde ser organizada a educação especial em uma aldeia indígena.

Este texto primeiramente apresenta algumas características da educação ofertada na aldeia de Santa Rosa do Oco’y; em seguida aponta as bases legais para o atendimento educacional especializado e o processo abertura da sala de recursos multifuncionais, finalizando com uma reflexão acerca da educação da pessoa com deficiência neste local.

\section{Algumas características educação na aldeia de Santa Rosa do Oco’y}

Na aldeia de Santa Rosa do Oco’y há aproximadamente 140 famílias, cujos filhos estão matriculados no Colégio Indígena Teko Ñemoingo que oferta a Educação Infantil; Ensino Fundamental Anos Iniciais; Ensino Médio; Educação de Jovens e Adultos, e oferta do espanhol como língua estrangeira. Nesse rol de modalidades inclui-se a recente inserção da Educação Especial às pessoas com deficiência.

As políticas públicas para os indígenas podem ser observadas nos principais documentos produzidos pelo governo. Tais elaborações ganham força na década de 1970 com o Estatuto do Índio, em 1973, e culminaram com a elaboração da Constituição de 1988. Posteriormente, na década de 1990, a educação escolar indígena emerge novamente na Lei de Diretrizes e Bases da Educação Nacional (LDBN) n. 9.394/96, que consolida definitivamente os direitos dos indígenas a uma educação diferenciada, e o atendimento às especificidades culturais.

Cavalcanti (1999) afirma que “a Constituição Federal reconhece aos povos indígenas o direito à educação bilíngue e intercultural”. A autora ainda reconhece que foi somente em 1991 que a educação indígena foi introduzida na Constituição Federal brasileira como sendo de responsabilidade do governo (CAVALCANTI, 1999, p. 395).

A Constituição Brasileira garantiu aos índios o direito de continuar na sua condição de indígena e, manter sua identidade indígena. A escola, por sua vez, nesse contexto, assume um papel importante como instrumento de valorização da língua, dos saberes, da tradição e da cultura indígenas.

A LDBN n. 9394/96, que tem como base a Constituição de 1988, garante que " $\mathrm{O}$ ensino fundamental regular será ministrado em língua portuguesa, assegurada às comunidades indígenas a utilização de suas línguas maternas e processos próprios de aprendizagem” (BRASIL, 1996, art. 32, inciso 3). Esta lei prevê a oferta de educação escolar com objetivo de fortalecimento das práticas socioculturais, com a recuperação de suas memórias históricas, reafirmação de suas identidades e acesso aos conhecimentos técnico-científicos da sociedade nacional. 
Outras normativas emergem também nos documentos como Referencial Curricular para Escolas Indígenas (1998). Este preconiza a regulamentação da escola indígena norteando tal instituição a organizar-se em sua estrutura e funcionalmente.

O Colégio Estadual Indígena Teko Ñemoingo está estruturado de acordo com os referidos documentos oficiais e estabelece-se nos preceitos de sua comunidade. É o local onde os indígenas têm oportunidade de aprender a ler e a interpretar as leis, a se apropriar dos conhecimentos tecnológicos e científicos da sociedade de modo a discutir seus direitos e a adquirir mais visibilidade para seu povo, além de garantir a valorização de sua cultura. A identidade dessa instituição de ensino diferenciado vem sendo ressignificada e se fortalecendo enquanto locus de formação de pessoas e, para tanto, reorganiza-se continuamente.

Até ano 2010, o colégio objeto de nossa pesquisa ofertava: Educação Infantil; Ensino Fundamental; Ensino Médio e Educação de Jovens e Adultos.

A Educação Infantil compreende a chamada educação pré-escolar, que atende crianças a partir dos 4/5 anos de idade. Em 2011, os professores eram indígenas e as turmas funcionavam no período vespertino. O Ensino Fundamental abrange os anos iniciais $\left(1^{\circ}\right.$ ao $5^{\circ}$ ano) e os anos finais ( $6^{\circ}$ ao $9^{\circ}$ ano). Em 2011, nos anos iniciais, os professores eram todos Avá-guarani e o funcionamento centrava-se nos períodos vespertino e matutino; já os anos finais tinham, em sua maioria, professores não indígenas e o funcionamento concentrava-se nos períodos matutino e vespertino.

O Ensino Médio contava com professores, em sua maioria, não indígenas. Possuía turmas no período matutino. A Educação de Jovens e Adultos (EJA) reunia turmas de Ensino Fundamental (Fase I e II, no período noturno) e de Ensino Médio (período noturno). Nesse segmento, havia professores indígenas e não indígenas, com o predomínio de professores não indígenas.

Como no ano de 2010 havia, nesta aldeia, seis alunos com deficiência, vislumbrou-se a possibilidade da oferta de atendimento educacional especializado, para que suas dificuldades e especificidades pudessem ter uma mediação intencional e com profissionais com formação em educação especial.

\section{Atendimento educacional especializado e breve histórico da abertura da sala de recursos}

O atendimento educacional especializado (AEE) é aquele “ofertado nas salas de recursos multifuncionais ou em centros de Atendimento Educacional Especializado da rede pública ou de Instituições comunitárias, confessionais ou filantrópicas sem fins lucrativos” (BRASIL, 2009, art. 1). 
Este atendimento tem como objetivo maior complementar ou suplementar a formação dos alunos em todos os níveis, etapas e modalidades de ensino.

Os principais documentos que subsidiam a política de inclusão escolar no Brasil, por meio do atendimento educacional especializado, são a Resolução $n^{0}$ 4, de outubro de 2009, que Institui as Diretrizes Operacionais para o Atendimento Educacional Especializado na Educação Básica, modalidade Educação Especial e o Decreto $n^{0} 7.611 / 11$, que dispõe sobre a educação especial, atendimento especializado e outras providências.

Os alunos com deficiência; com transtorno global do desenvolvimento; com altas habilidades/superdotação podem participar do AEE. O atendimento educacional especializado deve ser realizado:

[...] prioritariamente, na sala de recursos multifuncionais da própria escola ou em outra escola de ensino regular, no turno inverso da escolarização, não sendo substitutivo às classes comuns, podendo ser realizado, também, em centros de Atendimento Educacional Especializado da rede pública ou de instituições, comunitárias, confessionais ou filantrópicas sem fins lucrativos, conveniadas com a Secretaria de Educação ou órgão equivalente dos Estados, Distrito Federal ou dos Municípios (BRASIL, 2009, art. 5).

O atendimento na Sala de Recursos Multifuncional ocorre no período inverso ao da matrícula do aluno na rede regular de ensino. De acordo com a avaliação de uma equipe multidisciplinar, o aluno terá este atendimento indicado de duas a quatro vezes por semana. O professor que trabalha neste ambiente deve ter "[...] formação inicial que o habilite para o exercício da docência e formação específica para a Educação Especial (BRASI, 2009, art. 12).

O atendimento nas Salas de Recursos Multifuncional funciona nas seguintes áreas: Deficiência Intelectual, Deficiência Física Neuromotora, Transtornos Globais do Desenvolvimento e Transtornos Funcionais Específicos; Deficiência Visual; Surdez e Altas Habilidades/Superdotação. No Estado do Paraná, para orientar as ações para o cumprimento das leis e documentos oficiais que subsidiam a educação da pessoa com deficiência no país, foram criadas instruções. As instruções referentes à Sala de Recursos Multifuncional são:

Quadro 1 - Instruções do Estado do Paraná para as Sala de Recursos Multifuncional Tipo I

\begin{tabular}{|l|l|}
\hline INSTRUÇÃO & DESCRIÇÃO \\
\hline 002/2008 SUED/SEED & $\begin{array}{l}\text { Estabelece critérios para o funcionamento da Sala } \\
\text { de Recursos Multifuncional na área da Surdez. }\end{array}$ \\
\hline 020/2010 SUED/SEED & $\begin{array}{l}\text { Estabelece critérios para o funcionamento da Sala } \\
\text { de Recursos Multifuncional na área da Deficiência } \\
\text { Visual. }\end{array}$ \\
\hline
\end{tabular}




conclusão
\begin{tabular}{|l|l|}
\hline INSTRUÇÃO & DESCRIÇÃO \\
\hline 010/2011 (PARANÁ, 2011a) & $\begin{array}{l}\text { Estabelece critérios para o funcionamento de } \\
\text { Sala de Recursos Multifuncional Tipo I - Altas } \\
\text { Habilidades e Superdotação. }\end{array}$ \\
\hline 014/2011 (PARANÁ, 2011b) & $\begin{array}{l}\text { Estabelece critérios para o funcionamento da Sala } \\
\text { de Recursos Multifuncional Tipo I na Educação de } \\
\text { Jovens e Adultos. }\end{array}$ \\
\hline $016 / 2011$ (PARANÁ, 2011c) & $\begin{array}{l}\text { Estabelece critérios para o funcionamento da Sala } \\
\text { de Recursos Multifuncional Tipo I da Educação } \\
\text { Básica nas áreas da deficiência intelectual, } \\
\text { deficiência física neuromotora, transtornos globais } \\
\text { do desenvolvimento, transtornos funcionais } \\
\text { específicos. }\end{array}$ \\
\hline
\end{tabular}

Fonte: PARANÁ (2008); PARANÁ (2010); PARANÁ (2011a); PARANÁ (2011b); PARANÁ (2011c)

Estas instruções apresentam de forma detalhada os objetivos de cada atendimento, os alunos que devem ser atendidos, os critérios para a organização destas salas, a avaliação dos pretensos alunos e as atribuições dos professores para o trabalho nestes ambientes.

Já a Sala de Recursos Multifuncional da deficiência visual recebe do governo federal o Kit do MEC, adicionados os recursos de acessibilidade para alunos com esta deficiência como: impressora Braille; máquina de datilografia Braille; reglete de mão; punção; soroban, e outros.

Na aldeia de Santa Rosa do Oco’y, dentre os estudantes matriculados no ensino regular, havia seis alunos que apresentavam: Deficiência Intelectual (DI) e Deficiência Física Neuromotora (DFN), sendo que alguns eram atendidos na Pestalozzi em São Miguel do Iguaçu, hoje Escola Pestalozzi-Educação Infantil e Ensino Fundamental, na Modalidade Educação Especial. Diante dos documentos oficiais que determinavam o atendimento educacional especializado aos alunos com NEE e buscando os direitos do povo indígena, a Equipe do Núcleo Regional de Educação (NRE) de Foz do Iguaçu mobilizou-se buscando possibilidades de abertura de Sala de Recursos Multifuncional. Assim deram início ao processo e atendimento aos critérios da Instrução n. 016/2011 SUED/SEED (PARANÁ, 2011c) que estabelece que:

8.1 A direção da escola deve garantir espaço físico.

8.2 Alunos avaliados conforme orientações pedagógicas da SEED/DEEIN, regularmente matriculados e frequentando sala comum na Educação Básica da rede pública de ensino.

8.3 Professor especializado em cursos de pós-graduação em educação especial ou licenciatura plena com habilitação em educação especial ou 
habilitação específica em nível médio, na extinta modalidade de estudos adicionais e atualmente na modalidade normal.

8.4 Protocolar a documentação exigida de acordo com as orientações da SEED/CEF/DEEIN.

8.5 Encaminhar o protocolado para SEED/DEEIN para análise pedagógica e providências (PARANÁ, 2011c, p. 9-10).

Essas normativas trazem algumas questões que objetivam, além de fazer cumprir um direito ao atendimento especializado dentro da escola diferenciada, propõem que haja um espaço adequado às necessidades dos alunos, o cuidado com avaliação psicopedagógica seguindo as orientações da SEED. Regulamenta também que o professor deve estar preparado e ter formação relativa aos conhecimentos específicos. Demonstra certa preocupação em garantir que os professores estejam devidamente habilitados para o exercício da função de professor de educação especial, sobretudo, porque se trata de uma instituição de ensino que oferta a educação diferenciada na qual a cultura tem forte influência no processo de ensino e aprendizagem.

Como, nesta comunidade, havia apenas um colégio, que ofertava anos iniciais e finais do Ensino Fundamental, foram realizados dois processos: um que previa a autorização do funcionamento de uma sala de recursos multifuncionais, para o Ensino Fundamental anos iniciais e outra para o Ensino Fundamental anos finais/Ensino médio. As duas salas foram autorizadas, mas como eram poucos alunos, principalmente do Ensino Médio, o Departamento de Educação Especial e Inclusão Educacional (DEEIN) decidiu, juntamente com a equipe do NRE de Foz do Iguaçu, fazer um atendimento diferenciado das demais. Desta forma, foi autorizado o funcionamento de uma única Sala de Recursos Multifuncional que dava possibilidade de atender o Ensino Fundamental anos iniciais/finais e Médio, conseguindo assim matricular os alunos no Sistema Estadual de Registro Escolar (SERE).

Em 2011, foi concretizada a organização da Sala de Recursos Multifuncional tipo I que atendia os critérios apresentados na Instrução n. 016/2011 SUED/SEED (PARANÁ, 2011c). Assim, os seis alunos com deficiência que estavam matriculados no colégio em estudo passaram a participar do atendimento educacional especializado.

Outras conquistas em relação à educação da pessoa com deficiência, nesta escola, foram obtidas com um dos alunos com deficiência física neuromotora. Mesmo sendo atendido na Sala de Recursos Multifuncional, o aluno em questão recebeu um computador adaptado, é acompanhado por um Professor de Apoio à Comunicação (PAC) de acordo com a instrução n. 002/2012 SUED/SEED (PARANÁ, 2012) e um agente operacional. O professor de Apoio à Comunicação 
[...] é um profissional especializado, que atua no contexto da sala de aula, nos estabelecimentos de Ensino Fundamental, Ensino Médio e Educação de Jovens e Adultos, onde o apoio se fundamenta na mediação da comunicação entre o aluno, grupo social e o processo de ensino e aprendizagem, cujas formas de linguagem oral e escrita se diferenciam do convencionado (PARANÁ, 2012, p. 1).

Este profissional auxilia o aluno na sua comunicação na sala de aula, com os professores, com os outros alunos e todo o grupo envolvido. $\mathrm{O}$ agente operacional é responsável pela alimentação, higiene e também por levar o aluno aos diferentes ambientes da escola.

Atualmente, a Sala de Recursos Multifuncional atende cinco alunos, dos quais três têm deficiência intelectual e dois têm múltiplas deficiências (Deficiência Física Neuromotora e deficiência intelectual). Em 2013, equipamentos, mobiliários e materiais didáticos pedagógicos como: computadores; scanner; impressora laser; teclado com colmeia; mouse com entrada para acionador; bandinha rítmica; dominó; material dourado; esquema corporal; memória de numerais; tapete quebra-cabeça; dentre outros, foram recebidos para a utilização neste AEE.

\section{Perspectivas para a educação indígena dos alunos com NEE}

A educação escolar indígena e sua organização tem se pautado pelos documentos já referidos no início deste texto, o que coloca em diálogo, a escola indígena e as políticas públicas voltadas para o atendimento aos alunos indígenas com deficiência. Nesse contexto, a escola indígena valoriza o saber que vem de seus anciões que, dentre as particularidades culturais, defende maior aproximação entre a mãe e as crianças com algum déficit, dando-lhe um trânsito consentido à sala de aula. Nessa direção, a escola indígena se fundamenta em documentos específicos elaborados pelo governo do Estado do Paraná para o atendimento aos indígenas com deficiência.

De acordo com os dados do NRE de Foz do Iguaçu, atualmente, há um total de 275 alunos matriculados no Colégio Estadual Teko Ñ emoingo, sendo 80 matrículas nos anos iniciais do Ensino Fundamental; 93 matrículas de alunos nos anos finais do Ensino Fundamental; 32 matrículas no Ensino Médio; 65 matrículas na Educação de Jovens e Adultos e 05 matrículas nas Salas de Recursos Multifuncionais.

Neste sentido, podemos destacar que a busca por uma educação inclusiva requer muito esforço e luta. A busca por direitos conquistados só é possível com o conhecimento destas, que precisam ser socializada. No entanto, é preciso destacar que a educação inclusiva precisa ser “[...] compreendida como educação de qualidade para todos e não somente como acesso de alunos com necessidades educacionais especiais na rede regular de ensino" (PRIETO, 2002, p. 49). 
A educação inclusiva requer uma nova compreensão acerca da deficiência, diferente daquela em que o déficit é impedimento da aprendizagem e do desenvolvimento. De acordo com Góes (2002), apoiada nos pressupostos da abordagem histórico-cultural:

O desenvolvimento da criança com deficiência é, ao mesmo tempo, igual e diferente ao da criança normal. As leis de desenvolvimento são as mesmas, assim como as metas educacionais. Por outro lado, para se desenvolver e se educar, ela precisa de certas condições peculiares [...]. Logo, caminhos alternativos e recursos especiais não são peças conceituais secundárias na compreensão desse desenvolvimento (GÓES, 2002, p. 105-6).

Logo, toda pessoa com deficiência pode aprender e se desenvolver, no entanto, este processo depende, em grande medida, da qualidade de mediações que a criança recebe.

Desta forma o Atendimento Educacional Especializado, por meio da Sala de Recursos Multifuncional, foi de grande relevância para o ensino dos alunos que apresentam NEE na aldeia de Santa Rosa do Oco’y, pois têm a possibilidade de aprender com a utilização de diferentes recursos e com mediações específicas para as necessidades que possuem.

A equipe de educação especial do NRE de Foz do Iguaçu teve importante função na oferta deste atendimento no colégio desta comunidade e na busca por outros atendimentos necessários aos alunos que apresentam alguma deficiência. No entanto, é preciso que o ensino na sala de recursos realmente atenda às necessidades educacionais especiais dos alunos matriculados e que o trabalho realizado na sala regular seja organizado com a mesma finalidade para todos os educandos.

\section{Considerações finais}

Consideramos que ao realizarmos estudos com escolas em comunidades indígenas é importante marcar que as questões apresentadas tendem a demonstrar situações que se modificam continuamente, pois o povo indígena e seu desenvolvimento está atrelado ao contexto mais amplo das escolas indígenas de todo território nacional e, como tal, está em constante movimento, ou seja, a cada gestão da escola, os encaminhamentos tendem a mudar. Cada criança que inicia seu processo de formação esta estatística se movimenta, ora aumentando, ora diminuindo, num processo descontínuo apresentando tanto avanços, quanto retrocessos. A cada visita do cacique às instalações da escola, novas discussões se abrem e com elas novas demandas emergem.

Tal compreensão está calcada na perspectiva cultural de Cuche (1999), que fundamenta o caráter de incompletude em que se dá a formação das culturas e identidades. 
Em relação à educação do indígena com deficiência, na aldeia de Santa Rosa do Oco’y, consideramos que há, no presente momento, uma sinalização de avanço nos atendimentos educacionais especiais ali ofertados. Entretanto, tais ofertas devem estar em sintonia com a cultura local para que as práticas pedagógicas do professor objetivada nessa modalidade articule-se aos tipos de saberes que fazem sentido para aquele subgrupo, que tem em sua cultura especificidades que devem ser contempladas.

A Sala de Recursos Multifuncional tem sido considerada uma aliada no ensino dos alunos que apresentam NEE, pois conta com a participação ativa de um profissional com formação em educação especial, recursos diferenciados e a possibilidade de atendimento individualizado. Além de ter outros serviços conquistados por meio do NRE de Foz do Iguaçu, como: computador; Professor de Apoio à Comunicação e Agente Operacional.

Estes atendimentos demonstram o comprometimento da Equipe da Educação Especial em garantir AEE aos alunos indígenas, que apresentam alguma deficiência. O importante é que este processo continue sendo acompanhado. Que professores indígenas participem de cursos de formação para poderem atuar nestas áreas com a finalidade do atendimento dos alunos indígenas e na promoção da valorização de sua cultura dentro da modalidade da Educação Especial.

Tais estudos, voltados para a Educação Especial dentro da escola diferenciada, mostram que, embora a escola indígena esteja muitas vezes em áreas rurais e de pouco acesso aos meios de comunicação eletrônicos mais rápidos, ela mantém uma identidade enquanto instituição formadora, portanto, inserida no rol das escolas públicas do território nacional.

\section{Referências}

BRASIL. Estatuto do Índio. Decreto n. 6001, de 19 de dezembro de 1973. Dispõe situação jurídica dos índios ou silvícolas e das comunidades indígenas. Diário Oficial da União, Brasília, DF, 21 dez. 1973. Disponível em: <http://www.planalto.gov.br/ccivil_03/leis/16001.htm>. Acesso em: 11 mai. 2011.

BRASIL. Constituição da República Federativa do Brasil de 1988, Brasília: Senado Federal, 1988.

BRASIL. Lei de diretrizes e bases da educação nacional. Lei nº 9394/96. Brasília: Senado Federal, 1996.

BRASIL. Conselho Nacional de Educação. Resolução CNE/CEB $\mathbf{n}^{\mathbf{0}}$ 4/2009, que Institui Diretrizes Operacionais para o Atendimento Educacional Especializado na Educação Básica, modalidade Educação Especial. Brasília, 2009. 
BRASIL. Decreto $\mathbf{n}^{\circ}$ 7.611, que dispõe sobre a educação especial, o atendimento especializado e dá outras providências, de 11 de novembro de 2011. Brasília, 2011.

BRASIL. Ministério da Educação e do Desporto. Secretaria de Educação Fundamental. Referencial curricular nacional para as escolas indígenas. Brasília, DF: MEC/SEF, 1998.

CAVALCANTI, M. Estudos sobre educação bilíngue e escolarização em contextos de minorias linguísticas no Brasil. DELTA, Revista do Programa de Estudos Pós-Graduados em Linguística Aplicada da Pontifícia Universidade Católica de São Paulo, São Paulo, v. 15, p. 385-417, 1999.

CUCHE, Denys. A noção de cultura nas Ciências Sociais. Tradução de Viviane Ribeiro. Bauru: EDUSC, 1999.

GÓES, M. C. R. Relações entre Desenvolvimento Humano, Deficiência e Educação: contribuições da abordagem Histórico-Cultural. In: OLIVEIRA. M.K.; REGO, T. C.; SOUZA, D. T. R. (Org.) Psicologia, Educação e as Temáticas da Vida Contemporânea. São Paulo: Moderna, 2002. p. 95114.

HALL, S. Identidade cultural na pós-modernidade. Rio de Janeiro: DPA, 2004.

PARANÁ. Instrução 02/2008 SEED/SUED. Estabelece critérios para o funcionamento do Centro de Atendimento Especializado na Área da Surdez - CAES, serviço de apoio Especializado, no ensino regular. 2008. Disponível em: <http://www.educacao.pr.gov.br/arquivos/File/instrucoes/ instrucao022008sued.pdf $>$. Acesso em 12 ago 2013.

PARANÁ. Instrução 020/2010 SEED/SUED. Orientações para a organização e funcionamento do Atendimento Educacional Especializado na Área da Deficiência Visual. 2010. Disponível em: <http://www. educacao.pr.gov.br/arquivos/File/instrucoes/instrucao202010.pdf $>$. Acesso em 12 ago 2013.

PARANÁ. Instrução 010/2011 SEED/SUED. Estabelece critérios para o funcionamento da SALA de RECURSOS MULTIFUNCIONAIS TIPO I - para a Educação básica na Área das Altas Habilidades /Superdotação. 2011a. Disponível em: <http://www.nre.seed.pr.gov.br/umuarama/ arquivos/File/educ_esp/EDUC_ESP_2013/SRM_INST_10_2011_AH_S. PDF> Acesso em: 12 ago. 2013.

PARANÁ. Instrução 014/2011 SEED/SUED, que Estabelece critérios para o atendimento educacional especializado em Sala de Recursos Multifuncional -Tipo I na Educação de Jovens e Adultos - Fase I, Fase II e Ensino Médio - área da deficiência intelectual, deficiência física neuromotora, transtornos globais do desenvolvimento e transtornos 
funcionais específicos. 2011b. Disponível em: <http://www.educacao. pr.gov.br/arquivos/File/instrucoes/instrucao142011suedseed.pdf > . Acesso em: 12 ago. 2013.

PARANÁ. Instrução 016/2011 SEED/SUED, que Estabelece critérios para o atendimento educacional especializado em SALA DE RECURSOS MULTIFUNCIONAL TIPO I, na Educação Básica - área da deficiência intelectual, deficiência física neuromotora, transtornos globais do desenvolvimento e transtornos funcionais específicos. 2011c. Disponível em: <http://www.educacao.pr.gov.br/arquivos/File/instrucoes/ Instrucao162011.pdf > Acesso em: 12 ago. 2013.

PARANÁ. Instrução 002/2012 SEED/SUED, que Estabelece critérios para a solicitação de Professor de Apoio à Comunicação Alternativa para atuar no Ensino Fundamental, Ensino Médio e Educação de Jovens e Adultos. 2012. Disponível em: <http://www.educacao.pr.gov.br/arquivos/ File/instrucoes\%202012\%20sued\%20seed/Instrucao0022012suedseed. PDF>Acesso em: 12 ago. 2013.

PRIETO, R. G. A construção de políticas públicas de educação para todos. In: PALHARES, M. S.; MARINS, S. C. (Org.). Escola inclusiva. São Paulo: EdUFSCar, 2002. p. 45-60.

Data de submissão: 01/04/2014

Data de aprovação: 11/06/2014 